\title{
Raised enzyme markers of chronic inflammation in asymptomatic farmers' lung
}

\author{
C W G TURTON, G FIRTH, E GRUNDY, B G RIGDEN, J T SMYTH, \\ AND M TURNER-WARWICK
}

From the Department of Medicine (Thoracic Medicine), Cardiothoracic Institute, Brompton Hospital, London Centre for Medical Research, University of Sussex, Brighton, and Pulmonary Function Unit, Royal Devon and Exeter Hospital, Exeter.

ABSTRACT Subclinical inflammatory activity may be one of the factors which influences the variable natural history of farmers' lung. Serum lysozyme (LYS) and angiotensin converting enzyme (ACE) have been measured in 52 farmers with a previous history of farmers' lung and in 51 healthy control farmers. The group with farmers' lung assessed during the winter, although having had no recent acute symptoms, had significantly higher levels of LYS and ACE compared to both healthy control farmers seen in winter and farmers' lung subjects seen in summer. There was a mild but significant negative correlation between LYS and farm size in the farmers' lung subjects assessed in winter. The results suggest that active inflammation may be present in subjects with farmers' lung in the absence of acute symptoms during the season when dust exposure occurs as the result of feeding cattle.

Farmers' lung is an important cause of respiratory disability in rural communities. ${ }^{1-4}$ The disease was described nearly 50 years ago ${ }^{5}$ but important questions about both the pathophysiology and natural history have yet to be answered. Insidious progression in the absence of acute symptoms and the development of fibrosis cannot always be explained in terms of heavy continuous exposure. The individual factors which influence such courses are unknown.

Lysozyme (muraminidase) is a cytoplasmic enzyme found in inflammatory cells. Serum levels may be raised in chronic granulomatous inflammatory disorders including tuberculosis and sarcoidosis. ${ }^{6}$ Angiotensin converting enzyme (kininase) occurs in lung endothelial cells and serum levels are raised, particularly in sarcoidosis. $^{7}$ Clinical studies have suggested that increase of these enzymes is a marker of active chronic inflammation. ${ }^{7-10}$ In this paper we describe an attempt to detect subclinical inflammatory activity by measuring LYS and ACE in a group of working farmers who had been diagnosed previously as having farmers' lung but who had no acute symptoms at the time of study.

Address for reprint requests: Dr CWG Turton, Department of Medicine, Cardiothoracic Institute, Brompton Hospital, Fulham Road, London SW3 6HP.

\section{Methods}

The following criteria for the diagnosis of farmers' lung were used. (1) History: attacks of the following symptoms on at least two occasions after dust exposure: (i) breathlessness; (ii) cough; (iii) constitutional symptoms, for example, malaise, myalgia, or weakness; (iv) fever; (v) onset of symptoms between four and 12 hours after initial exposure. (2) Chest radiograph: transient abnormality during an attack, or evidence of pulmonary fibrosis in the absence of another cause. (3) Precipitating antibodies: presence in the serum of antibodies to Micropolyspora faeni or $M$ vulgaris.

The case was considered definite if at least four of the historical features were present with both an abnormal chest radiograph and positive precipitins. The case was considered probable if at least four of the historical features were present with either an abnormal chest radiograph or positive precipitins, or if there were at least two historical features present with both an abnormal chest radiograph and positive precipitins. Those with lesser evidence may have had farmers' lung but were excluded from this study.

Subjects with farmers' lung were ascertained from previous surveys of the agricultural com- 
munities around Exeter, Devon. ${ }^{2} 1112$ Eighty-nine patients were studied, 43 having been lost from follow-up and 16 declining to be visited. Arrangements were made by post for a visit. A questionnaire comprising details of farming practice, respiratory symptoms, and general health was completed. Venous blood was taken, serum separated the same day, and stored at $-20^{\circ} \mathrm{C}$. Three subjects with acute respiratory symptoms within one month of assessment were excluded as were 17 who failed to fulfil the above diagnostic criteria, 10 who no longer engaged regularly in farming, and seven on corticosteroid treatment.

Control farmers were ascertained from the records of a previous community survey ${ }^{11}$ and matched individually for age, sex, and smoking history as closely as possible. They were contacted and visited in the same way as those with farmers' lung. The fieldwork was done between May 1977 and December 1978. Details of the control and farmers' lung groups are shown in the table.

Serum LYS was estimated by spectrophotometric measurement of the rate of lysis of Micrococcus lysodeikticus as described by Litwack $^{13}$ with some modifications. ${ }^{10}$ Standards were prepared from a solution of human LYS extracted from the urine of patients with monocytic leukaemia. The results are expressed as "mg LYS per litre".

Serum ACE wes estimated by spectrophotometric measurement of the rate of hippuric acid release from benzoyl-glycyl-L histidyl-L leucine as described by Cushman and Cheung ${ }^{14}$ with minor modifications. ${ }^{10}$ ACE activity is defined as micromols of hippuric acid formed per minute under the assay conditions and expressed as units of ACE per litre of serum. Precipitins were detected by a standard Ouchterlony double diffusion technique, and by an enzyme-linked radioimmunosorbent (ELISA) test. $^{15}$

Table Details of subjects with farmers' lung and control farmers

\begin{tabular}{llrr}
\hline & & $\begin{array}{l}\text { Farmers } \\
\text { lung } \\
\text { subjects }\end{array}$ & $\begin{array}{l}\text { Control } \\
\text { farmers }\end{array}$ \\
\hline Total & Range & 52 & 51 \\
Age & Median & $23-69$ & $18-73$ \\
(yr) & 50 & 49 \\
Male: Female & Range & $51: 1$ & $47: 4$ \\
Farm size: & Median & $35-300$ & $15-400$ \\
Working alone & 145 & 155 \\
Using silage & & 29 & 21 \\
Chronic dyspnoea on exertion & 22 & 24 \\
Smokers & & 21 & 3 \\
& & 21 & 22 \\
\hline
\end{tabular}

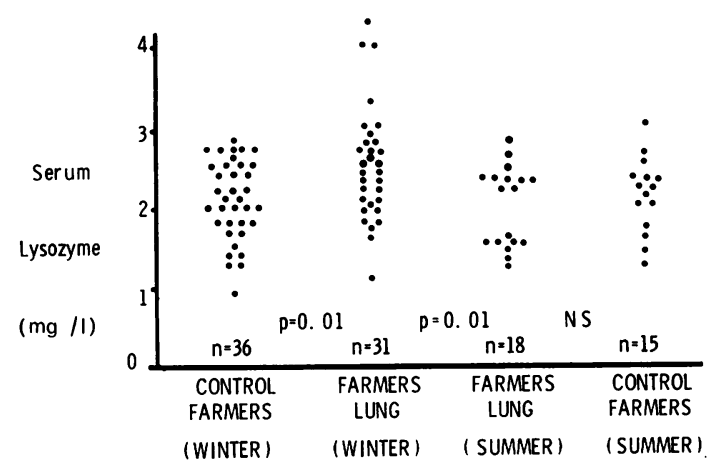

Fig 1 Serum lysozyme levels $(\mathrm{mg} / \mathrm{l})$ in control farmers winter, farmers' lung winter, farmers' lung summer, and control farmers summer groups.

Probability values $<0.05$ were considered significant. The statistical tests used are mentioned in the text.

\section{Results}

Figure 1 shows serum LYS levels in control farmers seen in winter, subjects with farmers' lung seen in winter, subjects with farmers' lung seen in summer, and control farmers seen in summer. LYS is elevated in the farmers' lung winter group, compared to both control farmers winter $(p=0.01$, Mann-Whitney $U$ test $)$ and farmers' lung summer group $(p=0.01$, MannWhitney $U$ test). Six of the farmers' lung winter group had LYS levels greater than two standard deviations above the mean of the control farmers winter group, and 13 had levels above the normal range. ${ }^{10}$ There was no significant difference between control farmers in winter and summer, or between farmers' lung summer, and control farmers summer groups.

Figure 2 shows serum ACE levels in control farmers winter, farmers' lung winter, and farmers' lung summer groups. ACE was elevated in farmers' lung winter compared with both control farmers winter $(\mathrm{p}<0.01, t$ test) and farmers' lung summer groups ( $\mathrm{p}<0.05, t$ test). Two of the farmers' lung winter group had levels above the normal range, ${ }^{10}$ which was similar to the range in control farmers. In the farmers' lung winter group correlations were sought between age, farm size, working without assistance, and the use of silage, and serum levels of both enzymes. Correlation coefficients were calculated for all possible pairings and significant values found for farm size against working alone $(r=-0.556, p<0.01)$ and LYS against farm 


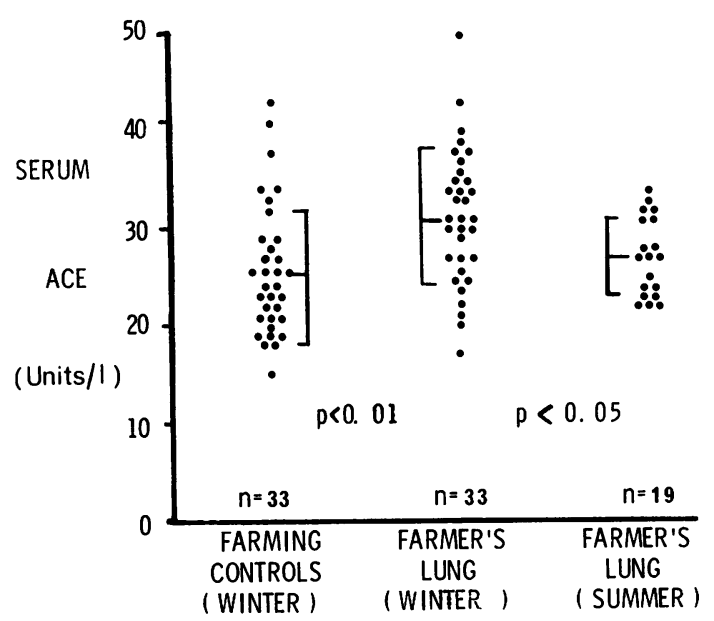

Fig 2 Serum ACE levels (units/l) in control farmers winter, farmers' lung winter, and farmers' lung summer groups. The bars indicate mean \pm 1 standard deviation.

size $(r=-0.378, p<0.05)$. Multiple regressions of LYS and ACE on the other factors were calculated. The only significant regression was LYS on size of farm ( $<<0.05)$, and this was not improved by any other factor. The results of Wilcoxon rank tests and Kruskal-Wallis analyses of variance in relation to working alone and use of silage against LYS and ACE were not significant. However, smaller farm size was associated with higher LYS $(p<0.025)$ and ACE $(p<0.05)$. There was no correlation between farm size and LYS or ACE in the farmers' lung summer or either control farmer groups. There was no correlation between serum precipitins and either LYS or ACE in any group. The slightly higher levels of LYS and ACE found in those with chronic breathlessness on exertion was not significant. LYS may have defined two subgroups within the farmers' lung summer group although the numbers are small (fig 1). These subgroups did not differ with respect to age, farm size, working alone, use of silage, or presence of chronic symptoms.

\section{Discu ssion}

Various selection forces may have operated on the subjects that were studied. The diagnostic criteria used are a compromise of the ideal and the practical. Lung biopsy can rarely be justified clinically, and the demands of agriculture make it difficult for farmers to travel miles to hospital for detailed lung function tests. Field studies, despite their attendant limitations, are necessary to investigate large numbers. Some subjects who failed to satisfy the criteria may have farmers' lung: memory for past illnesses is often indistinct and many do not have chest radiographs during respiratory illnesses. This study was confined to those still farming, thus excluding some who may have retired because of severe disease. Those taking oral corticosteroids, who may have more severe disease, were excluded because of the disease independent effect of these drugs on LYS and ACE levels. ${ }^{10}$ Some subjects identified by the previous surveys could not be visited either because of loss to follow-up or refusal. The factors contributing to this are unknown. The group was somewhat older than expected for a working agricultural community, perhaps because most were identified nearly 10 years before the current study.

The degree of dust exposure is very difficult to measure, and may be influenced by various factors. Small farms tend to be less modern and less prosperous: their farmers may not be able to afford to discard bad hay. Farmers working alone are unable to delegate the more dusty jobs and may thus be exposed more than those who have assistance. It may also be more difficult for the lone farmer to leave his farm or stop working when unwell. The positive correlation found between small farm size and working alone would be expected. Grass stored in silage ferments anaerobically which does not favour the growth of $M$ faeni, so farmers using silage might be exposed to less harmful dust.

The presence in the serum of subjects fulfilling criteria for farmers' lung (but with no recent symptoms) of elevated LYS and ACE only when they are regularly exposed to dust during the season when cattle are fed stored hay, and the lack of this seasonal variation in control farmers, suggests that some subjects may have chronic inflammatory activity even in the absence of acute symptoms. These enzymes have not been studied systematically during acute attacks of extrinsic allergic alveolitis. It has been recognised for some time ${ }^{16}$ that the onset of symptoms may be insidious, but the question as to whether elevation of LYS and ACE in the absence of acute symptoms relates to progressive disease and loss of function needs prospective study to be answered.

The only factor found to influence enzyme levels within the farmers' lung winter group was the mild but significant negative correlation between LYS and farm size, and the specific relationships between farm sizes of less than 
100 acres and higher LYS and ACE levels. The clinical observation has been made that the disease is more likely to develop in those working on small farms, ${ }^{17}$ but the farming practices that relate particularly to the development of farmers' lung have received little attention in the literature. The specific factor associated with small farm management which relates to higher LYS and ACE levels has not been identified in this study.

The results suggest that chronic inflammatory activity may exist in some subjects with farmers' lung when they are exposed regularly to potentially dangerous dusts in the absence of acute symptoms. The clinical indications for measuring LYS and ACE in farmers' lung are not established. Measurement is unhelpful for diagnosis because of lack of specificity. Increased levels may indicate a risk of progressive disease but further work is needed for this to be established.

We thank Dr Dilwyn Morgan, Dr John Edzcumbe, and many local general practitioners for their help. Miss $\mathbf{M}$ Rehahn gave invaluable statistical advice. The study was partly supported by the South-Western Regional Health Authority.

\section{References}

1 Grant IWB, Blyth W, Wardrop VE, Gordon RM, Pearson JCG, Mair A. Prevalence of farmers' lung in Scotland: a pilot survey. $\mathrm{Br}$ Med J 1972; 1:530-4.

2 Smyth JT, Adkins GE, Lloyd M, Moore B, McWhite E. Farmers' lung in Devon. Thorax 1975; 30:197-203.

3 Madsen D, Klock LE, Wenzel FJ, Robbins JL, Schmidt CD. The prevalence of farmers' lung in an agricultural population. Am Rev Respir Dis 1976; 113:171-4.

4 Braun SR, do Pico GA, Tsiatis A, Horvath E,
Dickie HA, Rankin J. Farmers' lung disease: long-term clinical and physiological outcome. $A m$ Rev Respir Dis 1979; 119:185-91.

5 Campbell JM. Acute symptoms following work with hay. Br Med J 1932; 2:1143-4.

6 Pascual RS, Gee JBL, Finch SC. Usefulness of serum lysozyme measurement in diagnosis and evaluation of sarcoidosis. $N$ Engl J Med 1973; 289:1074-6.

7 Leiberman J. Evaluation of serum angiotensionconverting-enzyme (ACE) level in sarcoidosis. Am J Med 1975; 59:365-72.

8 Selroos O, Klockars M. Serum lysozyme in sarcoidosis. Scand J Respir Dis 1977; 58:110-6.

9 Studdy P, Bird R, James DG, Sherlock S. Serum angiotensin-converting enzyme (SACE) in sarcoidosis and other granulomatous diseases. Lancet 1978; 2:1331-4.

10 Turton CWG, Grundy E, Firth G, Mitchell D, Rigden BG, Turner-Warwick $M$. Value of measuring serum angiotensin 1 converting enzyme and serum lysozyme in the management of sarcoidosis. Thorax 1979; 34:57-62.

11 Morgan DC, Smyth JT, Lister RW, Pethybridge RJ. Chest symptoms and farmers' lung: a community survey. Br J Ind Med 1973; 30:259-65.

12 Morgan DC, Smyth JT, Lister RW et al. Chest symptoms in farming communities with special reference to farmers' lung. $\mathrm{Br} J$ Ind Med 1975; 32:228-34.

13 Litwack G. Photometric determination of lysozyme activity. Proc Soc Exp Biol Med 1955; 89: 401-3.

14 Cushman DW, Cheung HS. Spectrophotometric assay and properties of the angiotensin-converting enzyme of rabbit lung. Biochem Pharmacol 1971; 20:1637-48.

15 Bamdad S. Enzyme-linked radioimmunosorbent assay test (ELISA) for IgG antibodies in farmers' lung disease. Clin Allergy 1980; 10:161-71.

16 Fuller CJ. Farmers' lung: a review of present knowledge. Thorax 1953; 8:59-64.

17 Chmelik F, do Pico GA, Reed CE, Dickie $H$. Farmers' lung. J Allerg Clin Immunol 1974; 54: 180-8. 